\title{
Enantioselective Synthesis of Diarylcyclopropanecarboaldehydes by Organocatalysis
}

\author{
Xuyun Chen ${ }^{\mathrm{a}}$, Yang $\mathrm{Yu}^{\mathrm{a}}$, Ziyang Liao ${ }^{\mathrm{a}}, \mathrm{Hao} \mathrm{Li}^{\mathrm{a}}{ }$, and Wei Wang ${ }^{\mathrm{a}, \mathrm{b}}, *$ \\ ${ }^{a}$ State Key Laboratory of Bioengineering Reactor, Shanghai Key Laboratory of New Drug Design, and School of Pharmacy, East China University of Science \\ and Technology, 130 Mei-long Road, Shanghai 200237, China \\ ${ }^{b}$ Department of Chemistry and Chemical Biology, University of New Mexico, Albuquerque, NM 87131-0001, USA
}

\section{ARTICLE INFO}

\section{ABSTRACT}

\section{Article history:}

Received

Received in revised form

Accepted

Available online

Keywords:

Diarylyclopropane

Enantioselective

Organocatalysis

Benzyl chloride

Cinnamaldehyde
An efficient synthetic method for chiral trisubstituted diarylcyclopropanecarboaldehydes has been developed from substituted benzyl chloride and $\alpha, \beta$-unsaturated aldehydes. The reactions were catalyzed by chiral amine catalyst under mild condition to afford the chiral diarylcyclopropanecarboaldehydes in good to high yields and up to excellent enantioselectivities.

2009 Elsevier Ltd. All rights reserved.

* Corresponding author. Tel./fax: +86 (21) 64253299 (H.L.); tel.: +1 (505) 277 0756; fax: +1 (505) 2772609 (W.W.).

E-mail addresses: hli77@ecust.edu.cn (H. Li),wwang@unm.edu (W. Wang). 
Cyclopropane, particular chiral cyclopropane, is one of the most important privileged core structures in natural products and biologically active compounds, ${ }^{1}$ which has inspired extensive synthetic effect for obtaining asymmetric multi-substituted cyclopropanations. ${ }^{2}$ Simmons-Smith cyclopropanation with chiral promoters could afford substituted cyclopropanes with high enantioselectivities., ${ }^{3,4}$ However, the methods rely significantly on metal catalysis, including $\mathrm{Rh},{ }^{5}$ Te ylide, ${ }^{6} \mathrm{Cu}$, $\mathrm{Zn},{ }^{8} \mathrm{Co},{ }^{9}$ and $\mathrm{Ru} .{ }^{10}$ In the last decade, organocatalysis, which is more environmental friendly than metal catalysis, has emerged as a new methodology to afford asymmetric cyclopropanes. For example, ammonium ylides was converted to cyclopropanes catalyzed by cinchona alkaloid. ${ }^{11}$ Iminium catalyzed cyclopropanation between enals and ylides could afford chiral trisubstituted cyclopropanes. ${ }^{12}$ Cyclopropanation of nitrostyrenes, enals or 2-arylidene-1,3-indandiones with halomalonates generated asymmetric cyclopropanes with good to high enatioselectivities. ${ }^{13-15}$

Among cyclopropanes, trisubstituted diarylcyclopropanes present special biological activities. For example, trisubstituted diphenyl cyclopropane amide derivative $\mathbf{A}$ is a potent inhibitor of purified renin (Scheme 1). ${ }^{16}$ Trisubstituted diarylcyclopropanehydroxamic acid derivative $\mathbf{B}$ has been developed as potent and selective class IIa histone deacetylase (HDAC) inhibitor for potential treatment of Huntington's disease. ${ }^{17}$ Trisubstituted diarylcyclopropane urea derivative $\mathbf{C}$ has been reported as potent orally available soluble epoxide hydrolase (sEH) inhibitor. ${ }^{18}$ However, efficient synthetic methods for constructing trisubstituted diarylcyclopropanes were still very rare. Recently, an improved Zn-catalyzed Simmons-Smith reaction was developed to synthesize 1,2,3-trisubstituted diarylcyclopropanes. ${ }^{19}$ Very recently, asymmetric synergistic catalysis of the cis-cyclopropanation of benzoxazoles has been reported. $^{20}$

Scheme 1. Trisubstituted diphenyl cyclopropane derivatives with biological activities.

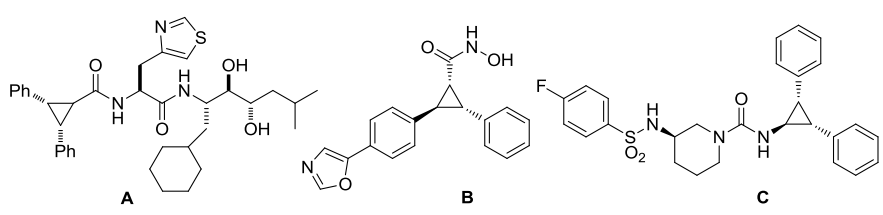

Our research focuses on the development of efficient methodology for construction of chiral scaffolds. For chiral cyclopropane synthesis, in 2007, we reported cascade Michaelalkylation reaction of $\alpha, \beta$-unsaturated aldehydes with bromomalonates for synthesis of chiral diester substituted cyclopropanes. ${ }^{21}$ Later on, electron-deficient arylmethanes were also demonstrated to react with $\alpha, \beta$-unsaturated aldehydes and form cyclopropanes. ${ }^{22}$ Based on our previous work, we envisioned that chiral trisubstituted diarylcyclopropanes could be constructed from electron-deficient benzyl chloride and $\alpha, \beta-$ unsaturated aldehydes. ${ }^{23}$

To test out our hypothesis, we initially tried reaction between 1-(bromomethyl)-2,4-dinitrobenzene 1a' $(0.33 \mathrm{mmol})$ and cinnamaldehyde 2a $(0.28 \mathrm{mmol})$ in $\mathrm{CH}_{3} \mathrm{CN}$ using diphenylprolinol TMS ether I $(30 \mathrm{~mol} \%)$ as the organo-catalyst and trimethylamine (TEA) as base under ambient air and temperature. Interestingly, the reaction for $11 \mathrm{~h}$ gave mainly a mixture of 2,4-dinitrobenzaldehyde from hydrolysis and oxidation of 1a' and a nucleophilic substitution product formed between 1a' and amine catalyst I. (table 1, entry 1). To avoid side reactions due to substitution and oxidation, the less reactive benzyl chloride 1a was used instead at same condition. To our delight, cyclopropane products (3a and $\mathbf{4 a}$ ) were isolated in $32 \%$ yield with some 2,4-dinitrobenzaldehyde obtained as well (entry
2). The reaction yield was further improved to $51 \%$ as well as good enantioselectivities for both $\mathbf{3 a}$ and $\mathbf{4 a}$ (92\% and $81 \%$ ee, respectively, entry 3) when 1a was added in four portions and reaction was performed under $\mathrm{N}_{2}$ atmosphere. When this reaction was performed at different solvents, it generally afforded two diasteromeric cyclopropane products in moderate yields and high enantioselectivities (entries 3-6). Reaction in diethyl ether gave the highest reaction yield but with compromised enantioselectivities (entry 7), while in toluene or dioxane, no cyclopropane products were separated (entries 8 and 9). For all solvents tested, 1,2-dichloroethane (DCE) seemed to give the best combination of yield, enantioselectivity and diastereoselectivity (entry 4). Therefore, DCE was chosen as the best reaction solvent. In terms of organocatalyst, four catalysts were screened. The more steric catalysts II and III afforded much higher yields while still retaining good enantioselectivities (entries 10 and 11). The enhanced yield was likely caused by the minimized nucleophilic substitution side reaction due to increased steric effects. By increasing the amount of $\mathbf{1 a}$ to 2 equiv., the reaction catalyzed by III gave the products in good yields with excellent enantioselectivities (entry 12). However, the reaction catalyzed by more steric catalyst IV gave much lower enantioselectivities (entry 13). Other bases such as 2,6-lutidine and $\mathrm{NaOAc}$ could not afford the product.

Table 1. Screening of the reaction conditions ${ }^{a}$

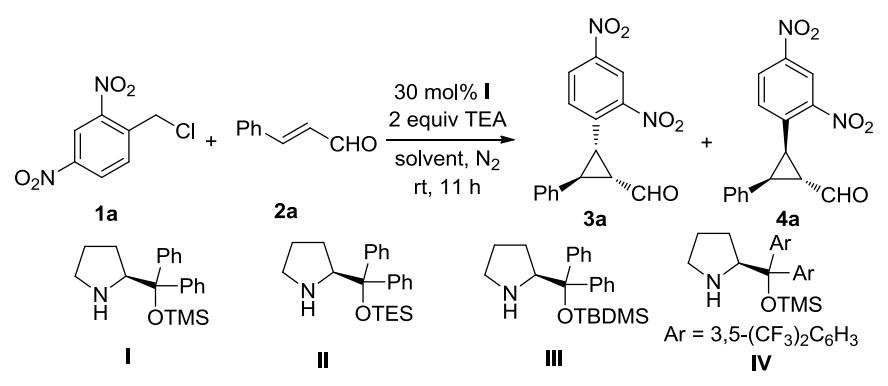

\begin{tabular}{|c|c|c|c|c|c|}
\hline entry & cat. & solvent & $\begin{array}{l}\text { yield\% }^{b} \\
(\mathbf{3 a}+\mathbf{4 a})\end{array}$ & $\begin{array}{l}\mathrm{ee} \% \\
(\mathbf{3 a} / \mathbf{4} \mathbf{a})^{c}\end{array}$ & $\begin{array}{l}\mathrm{dr} \\
(\mathbf{3 a}: \mathbf{4 a})^{d}\end{array}$ \\
\hline $1^{e f f}$ & I & $\mathrm{CH}_{3} \mathrm{CN}$ & trace & - & - \\
\hline $2^{f}$ & I & $\mathrm{CH}_{3} \mathrm{CN}$ & 32 & - & - \\
\hline 3 & I & $\mathrm{CH}_{3} \mathrm{CN}$ & 51 & $92 / 81$ & $2: 1$ \\
\hline 4 & I & $\mathrm{Cl}\left(\mathrm{CH}_{2}\right)_{2} \mathrm{Cl}$ & 55 & $92 / 89$ & $2: 1$ \\
\hline 5 & I & $\mathrm{CHCl}_{3}$ & 42 & $93 / 75$ & $1: 1$ \\
\hline 6 & I & THF & 54 & $95 / 87$ & $1: 1$ \\
\hline 7 & I & $\mathrm{Et}_{2} \mathrm{O}$ & 66 & $68 / 67$ & $3: 2$ \\
\hline 8 & I & toluene & - & - & - \\
\hline 9 & I & dioxane & - & - & - \\
\hline 10 & II & $\mathrm{Cl}\left(\mathrm{CH}_{2}\right)_{2} \mathrm{Cl}$ & 75 & $85 / 82$ & $1: 1$ \\
\hline 11 & III & $\mathrm{Cl}\left(\mathrm{CH}_{2}\right)_{2} \mathrm{Cl}$ & 72 & $88 / 85$ & $2: 1$ \\
\hline $12^{g}$ & III & $\mathrm{Cl}\left(\mathrm{CH}_{2}\right)_{2} \mathrm{Cl}$ & 74 & $96 / 94$ & $2: 1$ \\
\hline 13 & IV & $\mathrm{Cl}\left(\mathrm{CH}_{2}\right)_{2} \mathrm{Cl}$ & 65 & $25 / 39$ & $3: 2$ \\
\hline
\end{tabular}

${ }^{a}$ Reaction conditions: unless specified, a mixture of $2 \mathbf{a}(0.33 \mathrm{mmol})$, TEA $(0.56 \mathrm{mmol})$ and catalyst $(0.084 \mathrm{mmol})$ in $1.6 \mathrm{~mL}$ solvent was added the solution of $1 \mathrm{a}(0.28 \mathrm{mmol})$ in $4 \mathrm{~mL}$ solvent for 4 times and stirred for $11 \mathrm{~h}$ at rt.

${ }^{b}$ Isolated yield.

${ }^{c}$ Determined by chiral HPLC analysis.

${ }^{d}$ Determined by ${ }^{1} \mathrm{H}$ NMR.

e 2,4-Nitro benzyl bromide 1a' was used.

${ }^{f} \mathbf{1}$ was added in one port under air.

${ }^{g} \mathbf{2 a}(0.56 \mathrm{mmol})$ was used. 
Table 2. Scope of the synthesis of chiral cyclopropanes ${ }^{a}$

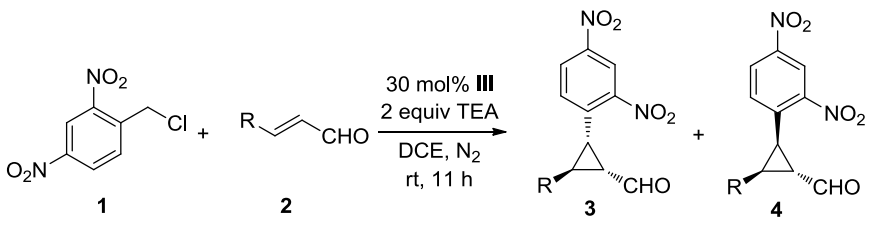

\begin{tabular}{lllll}
\hline entry & $\mathrm{R}$ & ${\text { yield }{ }^{b}(\mathbf{3}+\mathbf{4})}^{\mathrm{ee} \%(\mathbf{3} / \mathbf{4})^{c}}$ & $\mathrm{dr}(\mathbf{3 : 4})^{d}$ \\
\hline 1 & $\mathrm{Ph}(\mathbf{a})$ & 74 & $96 / 94$ & $2: 1$ \\
2 & $4-\mathrm{BrC}_{6} \mathrm{H}_{4}(\mathbf{b})$ & 66 & $90 / 95$ & $2: 1$ \\
3 & $4-\mathrm{ClC}_{6} \mathrm{H}_{4}(\mathbf{c})$ & 74 & $95 / 90$ & $1.5: 1$ \\
4 & $4-\mathrm{MeC}_{6} \mathrm{H}_{4}(\mathbf{d})$ & 76 & $95 / 94$ & $2: 1$ \\
5 & $4-\mathrm{MeOC}_{6} \mathrm{H}_{4}(\mathbf{e})$ & 68 & $93 / 86$ & $1: 1$ \\
6 & $3-\mathrm{FC}_{6} \mathrm{H}_{4}(\mathbf{f})$ & 81 & $91 / 92$ & $1.7: 1$
\end{tabular}

${ }^{a}$ Reaction conditions: unless specified, a mixture of $2(0.56 \mathrm{mmol})$, TEA $(0.56 \mathrm{mmol})$ and catalyst $(0.084 \mathrm{mmol})$ in $1.6 \mathrm{~mL}$ DCE was added the solution of $1 \mathrm{a}(0.28 \mathrm{mmol})$ in $4 \mathrm{~mL} \mathrm{DCE}$ for 4 times and stirred for $11 \mathrm{~h} \mathrm{at} \mathrm{rt}$.

${ }^{b}$ Isolated yield.

${ }^{c}$ Determined by chiral HPLC analysis.

${ }^{d}$ Determined by ${ }^{1} \mathrm{H}$ NMR.

With the optimal reaction condition in hand, we then focused on exploration of reactant scope of $\alpha, \beta$-unsaturated aldehydes for this asymmetric cyclopropanation reaction (Table 2). The results showed that $\alpha, \beta$-unsaturated aldehydes with substituted group at para- and meta- position of the phenyl ring afforded cyclopropane products $\mathbf{3}$ and $\mathbf{4}$ in modest to good yields and excellent enantioselectivities. Unfortunately, the diastereoselectivities of cyclopropanation products were not so attractive due to high structural similarity between two aromatic groups on the cyclopropane ring. Electron-withdrawing groups at para- position of the phenyl ring gave similar results as the unsubstituted cinnamaldehyde (entries 2 and 3). Electrondonating groups at para- position of the phenyl ring also reacted

Table 3. Scope of the synthesis of chiral cyclopropanes ${ }^{a}$

\begin{tabular}{|c|c|c|c|c|c|}
\hline R' & 2 & 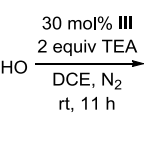 & 3 & 4 & $\mathrm{R}_{5}^{+} \overbrace{0}^{*}$ \\
\hline Entry & $\mathrm{R}^{\prime}, \mathrm{R}^{\prime}$ & $\mathrm{R}$ & $\begin{array}{l}\text { yield } \%{ }^{b} \\
(\mathbf{3}+\mathbf{4}+\mathbf{5})\end{array}$ & $\begin{array}{l}\mathrm{Ee} \% \\
(\mathbf{3} / \mathbf{4} / \mathbf{5})^{c}\end{array}$ & $\begin{array}{l}\mathrm{dr} \\
(3: 4: 5)^{d}\end{array}$ \\
\hline 1 & $\mathrm{NO}_{2}, \mathrm{NO}_{2}$ & $\begin{array}{l}2-\mathrm{BrC}_{6} \mathrm{H}_{4} \\
\text { (g) }\end{array}$ & 70 & $96 / 94 / 86$ & $2.5: 1: 1.5$ \\
\hline 2 & $\mathrm{NO}_{2}, \mathrm{NO}_{2}$ & $\begin{array}{l}2-\mathrm{ClC}_{6} \mathrm{H}_{4} \\
\text { (h) }\end{array}$ & 74 & $90 / 95 / 94$ & $3.4: 2.4: 1$ \\
\hline 3 & $\mathrm{NO}_{2}, \mathrm{NO}_{2}$ & $\begin{array}{l}2-\mathrm{MeOC}_{6} \mathrm{H}_{4} \\
\text { (i) }\end{array}$ & 86 & $95 / 94 / 39$ & $3: 1: 1.3$ \\
\hline $4^{e}$ & $\mathrm{NO}_{2}, \mathrm{CF}_{3}$ & $\begin{array}{l}4-\mathrm{ClC}_{6} \mathrm{H}_{4} \\
\text { (j) }\end{array}$ & 76 & $96 / 90 / 85$ & $1.5: 1.3: 1$ \\
\hline $5^{e}$ & $\begin{array}{l}\mathrm{CO}_{2} \mathrm{Me}, \\
\mathrm{NO}_{2}\end{array}$ & $\begin{array}{l}\text { 4- } \mathrm{ClC}_{6} \mathrm{H}_{4} \\
\text { (k) }\end{array}$ & 61 & $88 / 91 / 70$ & 1:1.7:1.1 \\
\hline $6^{f}$ & $\begin{array}{l}\mathrm{NO}_{2}, \\
\mathrm{CO}_{2} \mathrm{Me}\end{array}$ & $4-\mathrm{ClC}_{6} \mathrm{H}_{4}(\mathrm{I})$ & 61 & $96 / 90 / 80$ & $1.9: 1.5: 1$ \\
\hline
\end{tabular}

${ }^{a}$ Reaction conditions: unless specified, a mixture of $2(0.56 \mathrm{mmol})$, TEA $(0.56 \mathrm{mmol})$ and catalyst $(0.084 \mathrm{mmol})$ in $1.6 \mathrm{~mL}$ DCE was added the solution of $1(0.28 \mathrm{mmol})$ in $4 \mathrm{~mL} \mathrm{DCE}$ for 4 times and stirred for $11 \mathrm{~h}$ at $\mathrm{rt}$.

${ }^{b}$ Isolated yield.

${ }^{c}$ Determined by chiral HPLC analysis.

${ }^{d}$ Determined by ${ }^{1} \mathrm{H}$ NMR.

${ }^{e}$ The reaction was stirred for $7 \mathrm{~d}$ at $\mathrm{rt}$. smoothly to afford two products (entries 4 and 5). For 4methoxycinnamaldehyde, diastereoselectivity was decreased to 1:1 (entry 5). The reaction yield could reach to $81 \%$ when 3 fluorocinnamaldehyde was used (entry 6).

Interestingly, when 2-substituted cinnamaldehydes reacted with 1-(chloromethyl)-2,4-dinitrobenzene 1a, the third diastereomer 5 was detected as the minor product (Table 3). $\alpha, \beta$ Unsaturated aldehydes with electron-withdrawing groups at the ortho- position of the phenyl ring gave all three products in good yields and enantioselectivities (entry 1 and 2). For 2-methoxy cinnamaldehyde, cyclopropane products were obtained in a high yield of $86 \%$ with high enantioselectivities for only two products: $\mathbf{3 i}$ and $4 \mathbf{i}$. The enantioselectivity of the other product $\mathbf{5 i}$ dropped significantly $(39 \%$ ee, entry 3$)$. When a less electronwithdrawing methoxycarbonyl group replaced one nitro group in disubstituted benzylchlorides reacted with 2methoxycinnamaldehyde, no cyclopropane products were obtained. To our delight, for these less reactive disubstituted benzylchlorides including 1-(chloromethyl)-2-nitro-4(trifluoromethyl)benzene $\mathbf{1 j}$, methyl 2-(chloromethyl)-5nitrobenzoate $1 \mathbf{k}$, and methyl 4-(chloromethyl)-3-nitrobenzoate 11, 4-chlorocinnamaldehyde reacted smoothly to give acceptable reaction yields and high enantioselectivities, though extended reaction time up to several days were needed (entries 4-6). However, the reactions between benzylchloride and alkyl substituted $\alpha, \beta$-unsaturated aldehydes could not proceed under these reaction conditions, presenting a limitation for this method.

Scheme 2. The absolute configurations of $\mathbf{3 c}$ and $\mathbf{4 h}$.
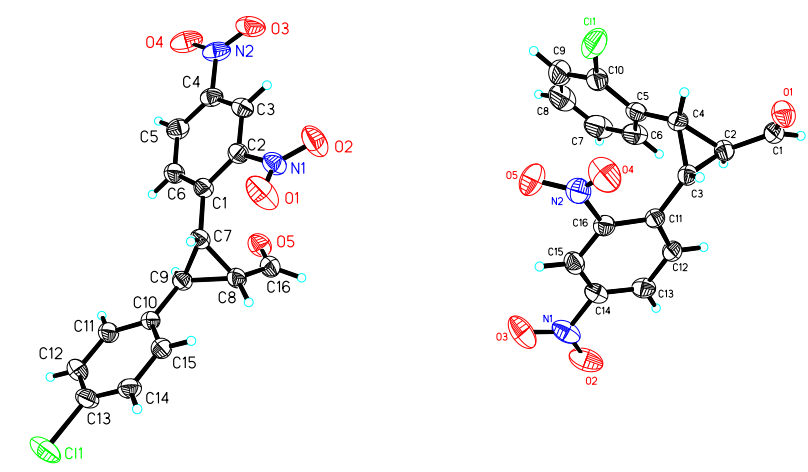<smiles>O=C[C@@H]1[C@H](c2ccc(Cl)cc2)[C@H]1c1ccc([N+](=O)[O-])cc1[N+](=O)[O-]</smiles><smiles>O=C[C@@H]1[C@@H](c2ccc([N+](=O)[O-])cc2[N+](=O)[O-])[C@H]1c1ccccc1Cl</smiles>

The absolute configurations of product $\mathbf{3}$ and $\mathbf{4}$ were determined by single crystal X-ray diffraction analysis based on compound 3c and $\mathbf{4 h}$ (Scheme 2). Unfortunately, we were not able to get good crystal of product $\mathbf{5}$ and solve its absolute configuration.

The proposed mechanism is described in Scheme 3. Activation of $\alpha, \beta$-unsaturated aldehyde 2 by a chiral organocatalyst III produces iminium A. Conjugate addition of a nucleophilic anion from $\mathbf{1}$, to the resulting active iminium $\mathbf{A}$, triggers a Michael process to afford intermediate $\mathbf{B}$. Then a nucleophilic substitution results in cyclopropane intermediate $\mathbf{C}$. Probably, the nucleophilic substitution can happen from both directions due to chloride at achiral $\beta$ position to give poor diastereoselectivities. Finally, water enters to recycle the catalyst III and afford products 3, 4 and 5.

\footnotetext{
${ }^{f}$ The reaction was stirred for $4 \mathrm{~d}$ at rt.
} 
Scheme 3. The proposed mechanism.

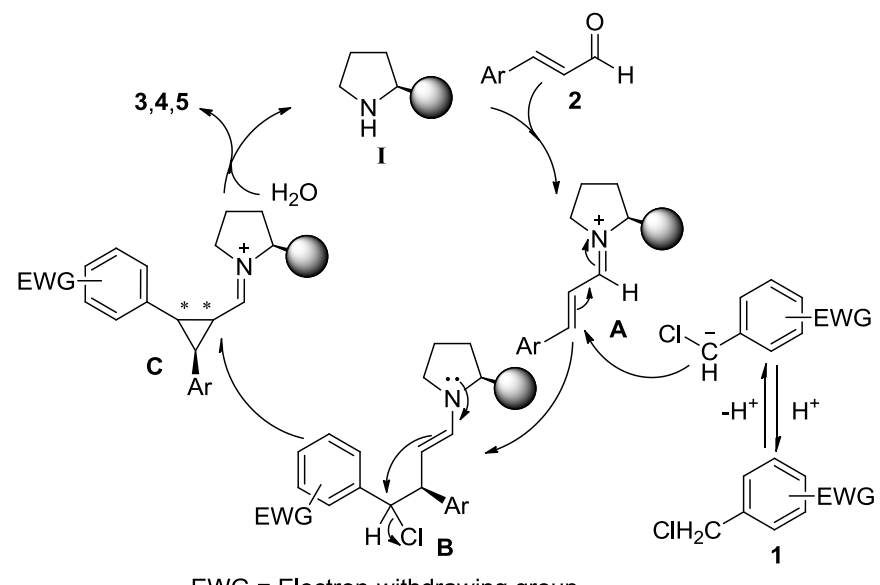

EWG $=$ Electron-withdrawing group

In summary, we have developed an efficient method for the synthesis of chiral trisubstituted diarylcyclopropanecarboaldehydes from substituted benzyl chloride and $\alpha, \beta$-unsaturated aldehydes. The reactions were catalyzed by chiral diphenylprolinol TBDMS ether under mild condition to give chiral diarylcyclopropanecarboaldehydes in good to high yields and overall excellent enantioselectivities. For $\alpha, \beta$-unsaturated aldehydes with substitutions at both para- and meta- position of the phenyl ring reacting with 1-(chloromethyl)2,4-dinitrobenzene afforded only two cyclopropane products, while the reactions of cinnamaldehyde with substitution at orthoposition or other disubstituted benzylchlorides generated three diastereomers. Further exploration of this methodology in synthetic applications towards biologically relevant molecules are under investigation in our laboratory.

\section{Acknowledgments}

Financial support of this research from the National Science Foundation of China (21372073, 21572054 and 21572055), the Fundamental Research Funds for the Central Universities and East China University of Science and Technology, and the China 111 Project (Grant B07023) is gratefully acknowledged.
Smith, H. V.; Jones, R. V. H.; Fieldhouse, R. Chem. Commun., 1997, 1785

6. Liao, W. W.; Li, K.; Tang, Y. J. Am. Chem. Soc., 2003, 125, 13030.

7. Rios, R.; Liang, J.; Lo, M.-C. Fu, G. C. Chem. Commun., 2000, 377.

8. Son, J. B.; Hwang, M.-h.; Lee, W.; Lee, D.-H. Org. Lett. 2007, 9, 3897.

9. Shitama, H.; Katsuki, T. Chem. Eur. J. 2007, 13, 4849.

10. Nishiyama, H. Top. Organomet. Chem. 2004, 11, 81.

11. Papageorgiou, C. D.; Cubillo de Dios, M. A.; Ley, S. V.; Gaunt, M. J. Angew. Chem., Int. Ed. 2004, 43, 4641.

12. Kunz, R. K.; MacMillan, D. W. C. J. Am. Chem. Soc. 2005, 127, 3240 .

13. McCooey, S. H.; McCabe, T.; Connon, S. J. J. Org. Chem. 2006, 71,7494 .

14. (a) Rios, R.; u n n, H.; Vesely, J.; Zhao, G.-L.; Dziedzic, P.; o v , A. Adv. Synth. Catal. 2007, 349, 1028. (b) Ibrahem, I.; Zhao, - Rios, R s , u n n, H i i o v , A. Chem. - Eur. J. 2008, 14, 7867.

15. Russo, A.; Meninno, S.; Tedesco, C.; Lattanzi, A. Eur. J. Org Chem. 2011, 5096

16. Martin, S. F.; Austin, R. E.; Oalmann, C. J.; Baker, W. R.; Condon, S. L.; deLara, E.; Rosenberg, S. H.; Spina, K. P.; Stein, H. H.; Cohen, J.; J. Med. Chem. 1992, 35, 1710.

17. Bürli, R. W.; Luckhurst, C. A.; Aziz, O.; Matthews, K. L.; Yates, D.; Lyons, K. A.; Beconi, M.; McAllister, G.; Breccia, P.; Stott, A. J. J. Med. Chem. 2013, 56, 9934.

18. Takai, K.; Chiyo, N.; Nakajima, T.; Nariai, T.; Ishikawa, C.; Nakatani, S.; Ikeno, A.; Yamamoto, S.; Sone, T. Bioorg. Med. Chem. Lett. 2015, 25, 1705.

19. Lévesque, E.; Goudreau, S. R.; Charette, A. B. Org. Lett. 2014, 16,1490 .

20. Meazza, M.; Light, M. E.; Mazzanti, A.; Rios, R. Chem. Sci. 2016, $7,984$.

21. Xie, H.; Zu, L.; Li, H.; Wang, J.; Wang, W. J. Am. Chem. Soc. 2007, 129, 10886

22. Li, T.; Zhu, J.; Wu, D.; Li, X.; Wang, S.; Li, H.; Li, J.; Wang, W. Chem. - Eur. J. 2013, 19, 9147.

23. When we prepared the manuscript, similar research was published: Meazza, M.; Ashe, M; Shin, H. Y.; Yang, H. S.; Mazzanti, A.; Yang, J. W.; Rios, R. J. Org. Chem. 2016, $81,3488$.

\section{References and notes}

1. (a) Ye, T.; McKervey, M.A. Chem. Rev. 1994, 94, 1091. (b) Lebel, H.; Marcoux, J.F.; Molinaro, C.; Charette, A.B. Chem. Rev. 2003, 103, 977. (c) Brandi, A.; Cicchi, S.; Cordero, F.M.; Goti, A. Chem. Rev. 2003, 103, 1213. (d) Baldwin, J.E. Chem. Rev. 2003, 103, 1197. (e) Shi, M.; Lu, J.M.; Wei, Y.; Shao, L. X Acc. Chem. Res. 2012, 45, 641.

2. (a) Doyle, M. P.; Forbes, D. C. Chem. Rev. 1998, 98, 911. (b) Salaün, J. Chem. Rev. 1989, 89, 1247.

3. (a) Simmons, H. E.; Smith, R. D. J. Am. Chem. Soc., 1958, 80, 5323. (b) Simmons, H. E.; Smith, R. D. J. Am. Chem. Soc., 1959, 81,4256 .

4. Pellissier, H. Tetrahedron, 2008, 64, 7041.

5. (a) Davis, H. M. L.; Bruzinski, P. R.; Lake, D. H.; Kong, N.; Fall, M. J. Am. Chem. Soc., 1996, 118, 6897. (b) Aggarwal, V. K.; 


\section{Graphic Abstract}
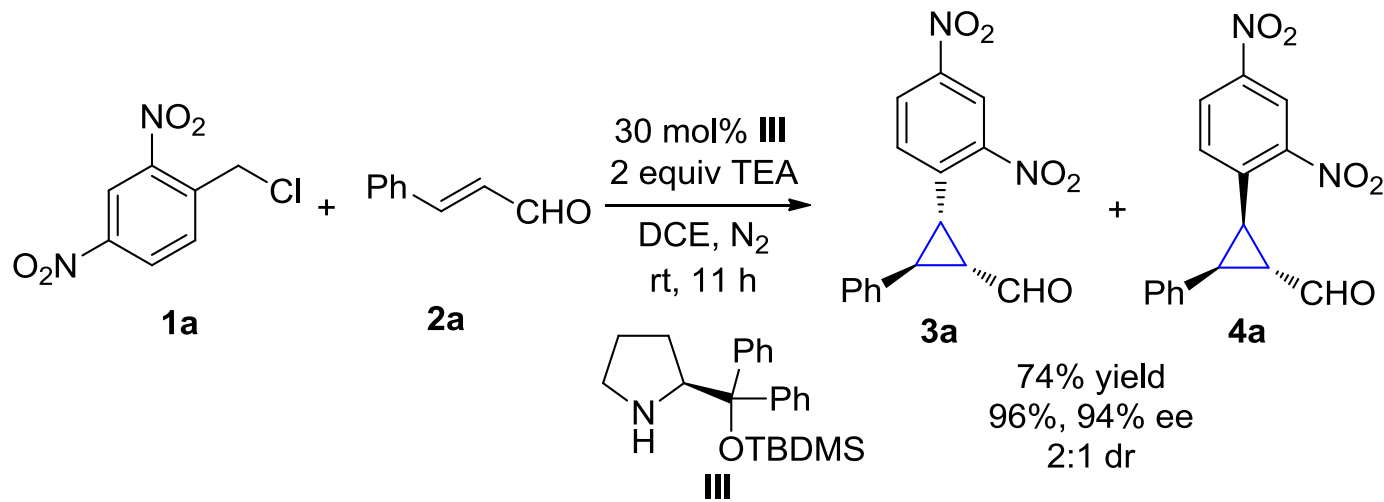